\title{
Coming Into His Shop From a Bright Afternoon · James Galvin
}

Like a local flurry or stars too small to use that spilled, iron filings stain the dirt floor silver.

In the center of the floor, the forge, in the center of the forge, the rose the bellows angers.

He lights a cigarette on rose colored steel then hammers the steel over the anvil's snout.

each strike.

Red sprays of sparks splash from

One gummy fly-specked window begins to allow a sprawl of wrenches, brushes, punches, chisels, taps, gouges . . .

Coalsmell.

Sweat.

The distant blue his eyes are.

There is a lathe

and milling machine, both homemade from scraps.

He chooses a

lighter hammer.

Now I can read the names on varnish cans and see how the walls are layered under sawblades, snowshoes, an airplane propeller, a loom.

On the other side of the door at my back, the light I came in from grows white like a blizzard or hot steel.

Hammer blows ring across the meadow too much like bells.

$\mathrm{He}$ is shaping a piece of earth.

$\mathrm{He}$ is hammering it into what he wants.

He thrusts it back into the fire when it loses its blush. 